\title{
Descripción de los tributos extrafiscales de índole ambiental y la problemática que los rodea. El caso ecuatoriano
}

\author{
Judith Yánez Villavicencio*
}

\begin{abstract}
RESUMEN
Este artículo analiza la problemática teórica y práctica que encarnan los impuestos ambientales que han sido creados con fundamento en los nuevos propósitos de la política tributaria ecuatoriana. Para la reflexión, se inicia describiendo la esencia que los capitanea y que tiene relación con su principal objetivo, esto es de incidir en quienes encabezan la contaminación, internalizando las fallas del mercado que implican exacerbados costos sociales sufridos por el colectivo. También se aborda cuál es el destino del recaudo de este tipo tributario y su coordinación con la satisfacción de necesidades públicas. Finalmente, se estudia al principio de capacidad contributiva con un enfoque de solidaridad colectiva, a la sazón y observancia de postulados constitucionales.
\end{abstract}

Palabras Clave: impuestos ambientales, política tributaria, necesidad pública, destino del recaudo, capacidad contributiva.

\section{ABSTRACT}

This article analyzes the theoretical and practical issues which the environmental taxes created on the basis of the new ends being pursued by the Ecuadorian tax policies entail. This reflection begins by describing the essence behind them, and which bears relationship with its core objective: i.e., to influence those who lead the fight against contamination, internalizing market failures which imply exacerbated social costs having an impact on the community. It also broaches on the destination of the revenues derived from this sort of tax and the pertinent coordination to address public needs. Finally, the contributive capacity principle is studied from a community solidarity approach, bearing in mind and observing the pertinent constitutional principles.

KEYWORDs: environmental taxes, tax policies, public needs, destination of revenues, contributive capacity.

* Asesora en Patrocinio, Ministerio de Defensa Nacional. 


\section{LA EXTRAFISCALIDAD Y LA MOTIVACIÓN QUE APUNTALÓ POLÍTICAS PÚBLICAS A FAVOR DEL AMBIENTE}

D esde el punto de vista teórico, los impuestos ambientales surgieron como una solución para internalizar los costes sociales-ambientales mediante la imposición tributaria orientada a atenuar las fallas de mercado y el actuar del ser humano que repercuten en el entorno natural. El fundador de esta modalidad de intervencionismo Estatal fue el economista Arthur Cecil Pigou, ${ }^{1}$ quien, a través de su teoría de la economía de bienestar, propuso la creación de impuestos de índole ambiental. ${ }^{2}$

En este sentido, las ciencias económicas han concitado nociones de capital importancia para la sustentabilidad del desarrollo, entre ellas la determinación de la nueva falla de mercado asentada en lo que se denominó externalidades negativas, que de primera mano Pigou las definió como "la divergencia entre el producto neto marginal social y el producto neto marginal privado", ${ }^{3}$ y más tarde sin perder el horizonte de su aparecimiento, Tibor Scitovsky las denominó como externalidades tecnológicas, constituyéndose en los supuestos que estimularon la acción del sector público para regular la ausencia de eficiencia del sistema libre de precios, donde se desarropó que el mercado no recibía las señales adecuadas y producía más de lo que requería. Ante esta problemática social y económica que hacía colisionar las posiciones del crecimiento económico con el desarrollo sustentable, surgió como solución la utilización de mecanismos tributarios para ajustar esa divergencia. De ello que, en palabras de Andrew Leicester, ${ }^{4}$ la fisura del coste social marginal que no estaba siendo contabilizado en el coste marginal privado, que era significativamente menor al primero, formó el germen para que los contaminadores paguen a través del devengo del tributo ambiental por la contaminación que han provocado, con lo cual se materializa la generación del máximo de bienestar social propugnado por Pigou.

Ahora, acentuando esta temática al campo práctico, a través del legítimo uso del poder tributario más la experiencia de los estados europeos, a fin de aplacar la deuda social y ecológica, en Ecuador se crearon ex novo los impuestos verdes con impacto en

1. Se ha de considerar que los impuestos ambientales son también conocidos como impuestos pigouvianos, Arthur Cecil Pigou, The Economics of Welfare (Londres: Macmillan and Co., 1920); Arthur Pigou, A study in public finance (Londres: Macmillan and Co., 1928).

2. "Después de la Conferencia de Río 1992, toma mayor fuerza la concepción ambientalista, vinculada con la legislación que regula actividades productivas y extractivas y promociona el desarrollo sustentable como eje rector de las mismas", Veáse en Revista Geoecuador (2008). Disponible en 〈http://www.pnuma.org/deat1/pdf/ Ecuador\%20pdf/09.\%20Capitulo\%207.\%20Politicas\%20ambientales.pdf .

3. Asociación Argentina de Estudios Fiscales, edit., Tratado de tributación (Ciudad de Buenos Aires: Astrea, 2003).

4. Andrew Leicester, "Tributación medioambiental: Principios económicos y experiencia en el Reino Unido", en Energía y tributación ambiental (Madrid: Marcial Pons, 2013), 32. 
objetos que causan efecto invernadero y materiales plásticos, que en teoría reproducen símiles de raigambre europea, cuyos postulados han sido moldeados, entre otros, por la Organización para la Cooperación y el Desarrollo Económico (OCDE) y la Agencia Internacional de la Energía (IEA), quienes los ha definido como "aquellos cuya base imponible consiste en una unidad física (o similar) de algún material que tiene un impacto negativo, comprobado y específico, sobre el medioambiente". ${ }^{5}$ Por ello la inserción de la extrafiscalidad en el marco normativo ecuatoriano obedece a los nuevos mandatos constitucionales vigentes, donde la política fiscal, ${ }^{6}$ coordinada con la política económica, ha revolucionado circunscribiendo la nueva era en la que los tributos cumplen con otras finalidades constitucionalmente aceptadas en beneficio social, como es el cuidado del medioambiente, indispensable para la existencia misma de la humanidad, máxime cuando este ordenamiento jurídico ha robustecido el derecho al ambiente sano y ha consagrado a la Naturaleza o Pachamama ${ }^{7}$ como sujeto de derechos.

En cuanto al límite que moldea la extrafiscalidad, la diagramación constitucional vigente en Ecuador no permite que la herramienta tributaria se vea desconexa de los elementos que fundan la razonabilidad de su presencia; de allí que es imperativo citar a Naveira de Casanova Gustavo, ${ }^{8}$ quien propuso los límites que la enmarcan: a) morigerada consideración de capacidad económica, b) consideración de un fin público; c) adecuación como medio al fin buscado; y d) respeto al sistema económico y a la propiedad. Por tanto, la activación de los tributos extrafiscales ambientales debe adecuarse a una respetuosa política pública ${ }^{9}$ que cristalice los objetivos y deberes del Estado plasmados en la Constitución, sin mermar otros derechos.

El artículo 85 de la Constitución de la República del Ecuador ${ }^{10}$ enmarca la forma y los criterios de cómo deben crearse las políticas públicas, y principalmente manda que

5. Organización para la Cooperación y el Desarrollo Económico/Agencia Internacional de la Energía, Environmentaltaxes- A statistical guide European Communities. Una apuesta por el establecimiento de impuestos verdes en países emergentes y en desarrollo (Quito: Fundación Friedrich Ebert Stiftung, 2012), 7. Disponible en 〈http:// library.fes.de/pdf-files/bueros/quito/09072.pdf).

6. Asamblea Nacional de la República del Ecuador, Constitución de la República del Ecuador (Montecristi, 2008). Disponible en 〈http:/www.asambleanacional.gov.ec/documentos/constitucion_de_bolsillo.pdf).

7. Ibíd., art. 71, La naturaleza o Pacha Mama, donde se reproduce y realiza la vida, tiene derecho a que se respete integralmente su existencia y el mantenimiento y regeneración de sus ciclos vitales, estructura, funciones y procesos evolutivos.

8. Pasquale Pistone, Estudios de derecho tributario constitucional e internacional: homenaje latinoamericano a Victor Uckmar (Buenos Aires: 2005), 311.

9. Enrique Saravia define a la política pública como "el sistema de decisiones gubernamentales que a través de acciones u omisiones procura modificar o mantener la realidad de uno o más sectores de la vida social por medio de la determinación de objetivos, y estrategias de actuación y de la asignación de recursos para alcanzar los objetivos establecidos". Véase Jefferson de la Torre, "Gestión de Políticas Públicas", Serie Académica Equinoccio, No. 2 (Quito: Universidad Tecnológica Equinoccial, s. a.).

10. Asamblea Nacional de la República del Ecuador, Constitución de la República del Ecuador, 2008. 
se deben orientar a hacer efectivo el buen vivir y otros derechos a partir del principio de solidaridad; con la única excepción en caso de que se amenacen otros derechos constitucionales, sin siquiera importar la prevalencia del interés general frente al particular, debe reformularse. En este aspecto, los impuestos extrafiscales en Ecuador están estrechamente relacionados con políticas públicas intervencionistas o directivas ${ }^{11}$ de índole económica en pro del medioambiente y del colectivo; que, de acuerdo a estudios realizados por la Comisión Económica para América Latina y el Caribe y por Euroclima, esta tendencia ha tomado cuerpo en América Latina a través de la reforma fiscal ambiental que apunta a un cambio estructural productivo, que vincula cada vez más a la política económica con el deseo de frenar la contaminación ambiental causante del nefasto cambio climático que se percibe, resguardando así derechos ciudadanos.

En consecuencia, el común denominador de los países es la búsqueda de la "sostenibilidad y sustentabilidad del medioambiente, complementada a la vez con metas distributivas, de innovación y de preservación de la competitividad". ${ }^{12}$ En esta línea, la legislación ecuatoriana plasma algunas normas que evidencian la aplicación de políticas fiscales y tributarias que viabilizan y complementan la reforma fiscal verde conforme consta en el Código Orgánico de la Producción, Comercio e Inversiones ${ }^{13}$ que dinamiza este objetivo a través de la promoción de uso de tecnologías ambientalmente limpias y de energías alternativas no contaminantes y de bajo impacto, que afianzan el uso racional de recursos y la prevención y control de la contaminación en los procesos productivos, diseñados a la luz de la ecoeficiencia y la producción sostenible.

\section{EL DESTINO DE LOS TRIBUTOS \\ EXTRAFISCALES AMBIENTALES Y SU CONEXIÓN CON LA NECESIDAD PÚBLICA}

Partiendo del postulado constitucional ecuatoriano dispuesto en el artículo 287 de la Norma Suprema, que indica: "Toda norma que cree una obligación financiada con recursos públicos establecerá la fuente de financiamiento correspondiente. Solamente las instituciones de derecho público podrán financiarse con tasas y contribuciones es-

11. Martul Ortega Perfecto Yebra, "Los fines extrafiscales del impuesto", en Andrea Amatucci, Tratado de derecho tributario: el derecho tributario y sus fuentes (Bogotá: Temis, 2001), 356.

12. José María Fanelli, Juan Pablo Jiménez e Isabel López Azcúnaga, La reforma fiscal ambiental en América Latina (Santiago de Chile: Naciones Unidas, 2015), 5. Disponible en «http://repositorio.cepal.org/bitstream/handle/ 11362/39782/S1501147_es.pdf;jsessionid=1C2F687E453F752541DC1085C43B3708?sequence=1).

13. Asamblea Nacional de la República del Ecuador, Código Orgánico de la Producción, Comercio e Inversiones, $R$. O. 351, 29 de diciembre de 2010. Disponible en 〈http://www.wipo.int/edocs/lexdocs/laws/es/ec/ec050es.pdf〉. 
peciales establecidas por ley", ${ }^{14}$ se hace visible un argumento preponderante financiero que enlaza el gasto público con el destino del ingreso obtenido mediante el recurso y, por sobre todo, resalta la fuente que debe cubrirlo. En este punto, vale destacar que, al ser los tributos una de las principales fuentes de ingresos del Estado para el sostenimiento público, abordar la premisa constitucional antes citada implica no solamente pensar en la relación financiera de presión fiscal y gasto público, sino también de una relación jurídica entre tributos y gasto público, ${ }^{15}$ máxime cuando estos pese a encontrarse conmistos son resueltos por cuerdas y tiempos separados.

Tómese en cuenta que en Ecuador la programación presupuestaria se la elabora cuatrienalmente ${ }^{16}$ tras aprobarse el Plan Nacional de Desarrollo, mientras que el Presupuesto General del Estado se lo esboza anualmente, y aún más paradójico resulta que estos se proyectan sobre la base de los tributos vigentes. En cualquier caso, retomando la tónica financiera, la dificultad radica en que los ingresos y gastos deben coordinarse en el ámbito de la programación económica del Estado, por el cual si el sistema financiero del lado del gasto está destinado a perseguir determinadas finalidades, y no puede contradecirse del lado del ingreso. Conforme esta temática, la congruencia tributaria aboga por que cada tributo sea coherente con su finalidad y con el sistema; sin embargo, en el caso de los impuestos extrafiscales ambientales, parte de la doctrina vacila en lo tocante al destino de su recaudo, sobre todo porque la corriente clásica que los nutre señala que debe destinarse para aminorar justamente las actividades nocivas con el ambiente.

Por estas razones, se pasa a analizar los puntos con los cuales surge incertidumbre atinente al destino de los impuestos ambientales. Una primera crítica surgió con la premisa financiera de Fernando Sainz de Bujanda ${ }^{17}$ quien, al regazo de la neutralidad del tributo y de la capacidad contributiva, pronunció que la injusticia no puede servir a la justicia, lo que involucra que un tributo por tener otro objetivo distinto al fiscal no deja de ser tributo en estricto sentido fiscal; por tanto, su recaudo naciente de la prestación coactiva asegura la cobertura del gasto público. Por el contrario, José Sánchez Galiana, quien considera los tributos ambientales como "aquellos que atienden principios o fines contenidos en la Constitución y que se pueden llevar a efecto mediante el estable-

14. Asamblea Nacional de la República del Ecuador, Constitución de la República del Ecuador, 2008, sec. Título V.

15. Eddy De la Guerra Z. enseñaba a los estudiantes que, partiendo de una mirada pragmática de la crónica presupuestaria, se requiere forjar una justa medida legal de racionalización del gasto público.

16. Véase la "Programación Presupuestaria Cuatrianual 2016-2019". Disponible en 〈http://www.finanzas.gob.ec/ wp-content/uploads/downloads/2015/11/34-Programaci\%C3\%B3n-Presupuestaria-Cuatrianual-2016-2019.pdf〉.

17. Fernando Sainz de Bujanda, Hacienda y Derecho (Madrid: Instituto de Estudios Políticos, 2015), 294. 
cimiento de tributos dirigidos fundamentalmente a la consecución de esa finalidad"18 sostiene que su destino debe acoplarse al fin propio de su arquetipo impositivo.

Para dilucidar las anteriores premisas, se profundiza hacia qué y a dónde se direccionan los ingresos tributarios provenientes de recursos extrafiscales, y, sin lugar a duda, la respuesta sería a satisfacer las necesidades públicas. No obstante, aunque lo dicho parece una literatura asimilable, debido a la coyuntura teórica que suponen las necesidades públicas dentro de la ciencia de las finanzas públicas, en virtud de ser su base y presupuesto existencial, conviene puntualizar qué se entiende por necesidad pública: tal vez la sola demanda expresa del pueblo al Estado, o una disposición normativa que encumbra una prestación estatal. Para Héctor Villegas, las necesidades públicas son las actividades que nacen de la vida colectiva y se satisfacen mediante la actuación del Estado, exigencias que se aumentan en razón directa a la civilización. ${ }^{19}$ Presupuesto este, que trasladado al contexto ecuatoriano que ha encumbrado derechos de avanzada, alcanzar el sumak kawsay, ${ }^{20}$ constituye una necesidad pública no solamente por configurarse como postulado constitucional, sino porque este aglutina derechos fundamentales, la vida digna, la salud, la vivienda, la educación, etc., que demandan prestación pública.

En consecuencia, se puede aseverar que las necesidades públicas por ser un clamor social son una conquista positivada en las normas, y por tanto exhortan satisfacción directa. Sin proponer mercantilizar los derechos ciudadanos que a la par son obligaciones estatales, conforme advierte Klaus Vogel, ${ }^{21}$ es sustancial no dejar de lado el aseguramiento de entradas para los presupuestos públicos; con esto se pone de relieve la necesidad de recabar ingresos para cumplir con los deberes contraídos, inclusive por medio de la extrafiscalidad maximizando su doble beneficio; de un lado, aunque sea en forma tenue ayude al recaudo; $y$, de otro, esencialmente preconice la intervención directa correctiva estatal incidiendo en el comportamiento de los administrados. De manera, después del mediano recorrido que se ha esbozado para derrocar lo planteado por Sainz de Bujanda, queda en buena manera lacerada su línea argumentativa, porque desde la perspectiva constitucional ecuatoriana se concluiría que las necesidades

18. José Antonio Sánchez Galiana, "Configuración y régimen jurídico de las tasas en el ordenamiento tributario español. Fiscalidad, parafiscalidad y extrafiscalidad”, en Andrea Amatucci, Dal diritto finanziario al diritto tributario: studi in onore di Andrea Amatucci (Bogotá: Temis/Jovene, 2012), 399.

19. Héctor B. Villegas, Ciencia de las finanzas y actividad financiera, 3a. ed. (Buenos Aires, 1984), 3.

20. El SENPLADES se aproxima al sumak kawsay como: "la vida plena, expresa en esta cosmovisión. Alcanzar la vida plena consiste en llegar a un grado de armonía total con la comunidad y con el cosmos", Secretaría Nacional de Planificación y Desarrollo (SENPLADES), "Plan Nacional del Buen Vivir 2009-2013", 2009. Disponible en 〈http://www.planificacion.gob.ec/wpontent/uploads/downloads/2012/07/Plan_Nacional_para_el_Buen_Vivir _(version_resumida_en_espanol).pdf).

21. Klaus Vogel, "Von einer Emeuerung des Allgemeinen Abgabenrechts in Deutschland", en Perfecto Yebra Martul Ortega, Los fines extrafiscales del impuesto (Bogota: Temis, 2002), 372. 
públicas reclaman un ambiente sano y equilibrado, objetivo conexo con la potestad de la política fiscal y económica que en conjunción con el deber de contribuiir ${ }^{22}$ justifican el nacimiento de tributos extrafiscales ambientales; así que un impuesto no puede ser catalogado como injusto por no ser primordialmente recaudatorio, ya que, según el contexto actual, lo justo se permea en clave de solidaridad social.

Ahora, para fundamentar lo alusivo a la tensión entre el ingreso y el destino de los tributos extrafiscales, motiva indagar si la imposición ambiental se desnaturaliza o no, al usar los fondos percibidos para fines diversos a su objetivo. Según Carolina Rozo Gutiérrez, ${ }^{23}$ dentro de la temática extrafiscal no resulta totalmente viable que el recaudo del impuesto extrafiscal se utilice solo para fines ambientales, pues advierte que la destinación específica que se otorgue a los tributos de carácter extrafiscal que pretenden desincentivar conductas in genere como las que atañan al medioambiente no son imperativas, dado que su afán recaudatorio es meramente subsidiario. Por ende, opina que, no siendo el factor recaudatorio el que direcciona esta clase de tributos, los ingresos que reporte deben destinarse a reducir las necesidades de los sectores más vulnerables de la población y no necesariamente debe financiar las actividades que el Estado promueve a través de dichas figuras. En este contexto, la hacienda pública provista de ingresos y gastos que son el móvil de la dinámica social y desarrollo estatal, por no ser un ente inteligible que se debe a un solo segmento social, ni peor aún a la selectividad exclusiva de sus gobernantes, no discrimina la función ingreso y destino del tributo, sino que, como un todo, cubre la elección de prioridades que se plasman como necesidades sociales.

En función de lo establecido, es factible quebrantar el pensamiento propugnado por De la Garza y Eusebio González, quienes indicaron que los tributos no destinados a cubrir el gasto público son inconstitucionales; ya que por la dualidad funcional que los imbrica, también mitigan la carga pública cumpliendo su objetivo intrínseco provocando en el agente contaminador el desfogue de un coste por el uso irracional del capital natural; simetría esta que cumple con las recomendaciones teóricas de Alberto Gago y Labandeira Villot Xavier, con la que los tributos ambientales, además de ser efectivos en términos ambientales, deben serlo también en términos fiscales. ${ }^{24} \mathrm{Sin}$ embargo, en el ámbito de las asignaciones, se complejiza en cierta forma la distribu-

22. Artículo 83, numeral 15 Constitución de la República del Ecuador: Son deberes y responsabilidades de las ecuatorianas y los ecuatorianos: Cooperar con el Estado y la comunidad en la seguridad social, y pagar los tributos establecidos por la ley.

23. Carolina Rozo Gutiérrez, "Las funciones extrafiscales del tributo a propósito de la tributación medioambiental en el ordenamiento jurídico colombiano", Foro: Revista de Derecho, No. 1 (2003): 170.

24. Gloria García Alarcón, "Son los tributos ambientales una opción para la financiación de las HHPP? Reflexiones sobre la fiscalidad ambiental autonómica”, Cuides, No. 9 (2012): 272. 
ción del ingreso debido a que el art. 271 de la Constitución indica que el porcentaje de participación que reciben los Gobiernos Autónomos Descentralizados (GAD) es "al menos el quince por ciento de ingresos permanentes y de un monto no inferior al cinco por ciento de los no permanentes correspondientes al Estado Central, excepto los de endeudamiento público", ${ }^{25}$ distribución que se realiza conforme los criterios del artículo 272 ejusdem en que taxativamente se indica que se atenderá al tamaño y densidad de la población, y a las necesidades básicas insatisfechas. ${ }^{26}$

El mismo postulado constitucional califica a dichas asignaciones como "predecibles, directas, oportunas y automáticas", estableciendo, además, que su transferencia opera desde la Cuenta Única del Tesoro Nacional a las cuentas de los GAD, pero en el plano estrictamente extrafiscal esta norma puede producir un riesgo relativo a su eficacia, ya que según el costo-beneficio que los GAD sientan percibir, debido a que por factores de producción o consumo en distintas jurisdicciones se produzca mayor contaminación, puede que de todas maneras estas reciban igual o mayor asignación que aquellos que aminoren la polución. Por esto es necesario complementar el sistema con incentivos tributarios a través de subvenciones o deducciones ligadas al beneficio ambiental para mitigar el uso irracional de recursos naturales que compensen la insuficiente ${ }^{27}$ asignación presupuestaria otorgada localmente.

Antonio Arnaldo, ${ }^{28}$ partidario de la delegación de aspectos secundarios de los impuestos a los gobiernos locales, opina que se les debe permitir un margen de acción propio y que se relaciona a la tarifa, para que según las circunstancias ambientales que perciban en su jurisdicción la modifiquen. No obstante, en cuanto al producto de la contaminación general como es el $\mathrm{CO}_{2}$ plasma una falencia en su argumento, ya que no siendo este proveniente de fuentes de emisión puntuales, y a propósito de dinamizar sus propias economías, podrían iniciar una competencia por morigerar los impuestos por emisiones a fin de atraer segmentos productivos e impulsar su industria, pervirtiendo al sistema. Lo cierto es que conforme la Programación Presupuestaria Cuatrianual 2016-2019 del Plan Nacional de Desarrollo ${ }^{29}$ se observa que, pese al discurso anticontaminación de la política tributaria, los objetivos ambientales se encuentran disgregados del desarrollo económico encumbrado, ya que estos ocupan apenas el $1,1 \%$ de todo el gasto tributario.

25. Asamblea Nacional de la República del Ecuador, Constitución de la República del Ecuador, 2008.

26. Ibíd.

27. Considero que las asignaciones son insuficientes ya que se busca de primera mano satisfacer necesidades públicas ajenas al cometido ambiental postergándolo.

28. Antonio Arnaldo, Los impuestos ambientales (Buenos Aires: Osmar D. Buyatti Librería, 2007), 204.

29. Véase "Clasificación del Gasto por Objetivo de Política", SENPLADES. Disponible en «http://www.finanzas.gob. ec/wp-content/uploads/downloads/2015/11/34-Programaci\%C3\%B3n-Presupuestaria-Cuatrianual-2016-2019. pdf〉. 
Felizmente para consolar el cometido extrafiscal, vale indicar que para medir su eficacia, su literatura propia subraya que, en esta temática, el poder regulatorio de los tributos no es necesariamente cuantificado en magnitud de asignaciones o inversiones en el sector, ya que fundamentalmente promueve el uso racional y eficiente de los recursos naturales, que puede ser encumbrado por medio de lo que Vicente Oscar Díaz bautizó como el fracaso recaudatorio, después de todo su interés no es en primer término fiscalista sino intervencionista y regulador.

\section{CONSIDERACIONES AL PRINCIPIO EL QUE CONTAMINA PAGA}

Antiguamente este principio suponía pagar por el derecho a contaminar; sin embargo, con el avance del derecho se lo ha repensado como el medio que permite aplicar el tributo ambiental a quien se beneficia del uso irracional de los recursos naturales, internalizando los costos de la contaminación; sin que esto, conforme explicó Lucy Cruz de Quiñónez, ${ }^{30}$ implique el sometimiento a un arbitrario o caprichoso intervencionismo que provoque distorsiones económicas.

En el concreto caso ecuatoriano, hasta el 21 de diciembre de 2017 se puede considerar al principio contaminador pagador (PCP) como indeterminado, ya que la norma que lo dota de contenido, y que se encuentra inserta en el Código Orgánico del Ambiente, aún no entra en vigencia. En ese código se estatuye que quien promueva una actividad contaminante debe incorporar a los costos de producción las medidas necesarias para prevenirla, evitarla o reducirla. De otra parte, para Aimée Figueroa Neri, el principio inglés el que contamina paga juzga por contaminador "a la persona física o jurídica de derecho público o privado que directa o indirectamente deteriora el medioambiente, o crea las condiciones para que se produzca dicho deterioro". ${ }^{31}$

Hilando fino, estos postulados más administrativos que tributarios podrían conectar la materia fiscal a través de la extrafiscalidad como hito vinculante para la determinación del sujeto pasivo y para repercutir cambiando su conducta. María Páez Medina amplía este punto reflexionando que la "ratio iuris de los gravámenes ambientales conduce a concluir que los contribuyentes que incurran en el comportamiento contaminante, tipificado en la ley como presupuesto de hecho deben soportar el

30. Lucy Cruz de Quiñónez, "Marco constitucional del derecho tributario", en La jurisprudencia tributaria del consejo de estado estudio (Bogotá: Instituto Colombiano de Derecho, 2004), 285.

31. Aimée Figueroa Neri, Fiscalidad y medio ambiente en México (México: Porrúa, 2000), 74. 
gravamen", ${ }^{32}$ esto sin olvidar que el principal objetivo es influir en la voluntariedad del agente contaminador, disuadiendo su comportamiento contaminante y/o persuadiendo conductas más amigables con el ambiente. En esta línea, la Corte Constitucional Colombiana lo ha caracterizado por "ajustar efectivamente el comportamiento de los agentes públicos y privados para que respeten y protejan los recursos naturales". ${ }^{33}$

En la esfera aplicativa del PCP se propende de manera directa corregir las fallas del mercado provocadas por las externalidades negativas, de ello que se recae sobre el fabricante o consumidor dependiendo de la materia que se desee morigerar en pro del ambiente. Por otra parte, se deja anotado que este principio encarna además una estrategia del Estado para no pervertir el sistema de protección al ambiente a través de subvenciones y subsidios que aumenten el gasto público; por ello se imputa al contaminador el coste social sufrido. No gravar actividades contaminantes sería un premio al medro individual esculpido a base del sacrificio del bienestar social, inocentada subvención social.

\section{COMENTARIOS AL IMPUESTO A LA CONTAMINACIÓN VEHICULAR}

Bajo la premisa de que Ecuador tiene una tributación ambiental incipiente, se puede calificar al Impuesto Ambiental la Contaminación Vehicular (IACV) como una figura impositiva precaria cuyo espíritu es extrafiscal pero su cuerpo es recaudatorio. Esta aseveración es previsible debido a que concisamente grava manifestaciones de riqueza y en menor grado la potencialidad de contaminación; prevé un sinnúmero de exoneraciones que descoordinan el cambio tecnológico, incide sobre el sujeto pasivo de iure (propietario del vehículo sea persona natural o jurídica-nacional o extranjera) y por ende el sujeto pasivo de facto queda excluido de soportar la carga tributaria pese a que también se ha beneficiado del ambiente y lo ha contaminado. ${ }^{34}$ Así también, el aspecto temporal del hecho generador del impuesto en mención evidencia otro desatino, ya que bajo la clasificación esbozada por Juan Martín Queralt ${ }^{35}$ el IACV deviene en un impuesto periódico-anual que, si bien compagina con el ejercicio permanente de

32. María Elena Páez Medina, "La capacidad contributiva en los tributos medioambientales" (tesis doctoral, Universidad de Salamanca, 2012), 193. Disponible en 〈http:/gredos.usal.es/jspui/bitstream/10366/115606/1/DDAFP_Paez_Medina_M_Elena_LaCapacidadContributivaTributosMedioambientales.pdf〉.

33. Corte Constitucional de Colombia, Jurisprudencia tributaria C-449/15, 2015. Se eliminó la palabra eventual ya que considero que no puede imponerse un tributo ambiental sobre eventualidades de contaminación.

34. Si se moldeara al IACV para que dimane preponderantemente el efecto de percusión, se morigeraría la contaminación.

35. Juan Martín Queralt y otros, Curso de Derecho financiero y tributario (Madrid: Tecnos, 2015), 73. 
la actividad contaminante, debido a los criterios que usa para fijar su cuántum (cilindraje y año del automotor), no grava en forma fidedigna picos de polución que, por el contrario, sería calculable en la medida en que se controlen factores como kilometraje y emisión de gases del vehículo a fin de regular el abuso en el recorrido del automotor, $\mathrm{y}$, por ende, el consumo de combustibles fósiles.

En lo concerniente al aspecto espacial ${ }^{36}$ del IACV, se puede asegurar que su hecho generador espacialmente ha sido determinado en forma implícita, limitado su accionar solamente por las fronteras y consigo la territorialidad de la ley. Esta circunstancia ambientalmente no resulta sostenible debido a que si se trabaja en pro del medioambiente, con el ánimo de mejorar la calidad del mismo, se deben tomar medidas y criterios distintivos para la aplicación de la imposición ambiental, quizás a nivel municipal (especialmente en las zonas más polutas) y dependiendo del parque automotor que exista.

Por otra parte, el citado impuesto supone una serie de exenciones atentatorias al principio de igualdad, ya que, al subsumir el desarrollo económico a base de costes sociales ambientales, la ley discrimina actividades igualmente nocivas para el ambiente dispensándolas del gravamen impositivo, generando un trato desigual a las actividades símiles (tóxicas).

Lo expresado es verificable con la lectura de la última reforma a la Ley Orgánica de Régimen Tributario Interno, ${ }^{37}$ por la cual vehículos exonerados del IACV ${ }^{38}$ son, entre otros: los de propiedad de las entidades del sector público, los destinados al transporte público de pasajeros, los vehículos de transporte escolar y taxis, los relacionados directamente con la actividad productiva del contribuyente, etc., lo que a breve rasgo en términos de fiscalidad ambiental conlleva un resquebrajamiento de la esencia del impuesto y del principio contaminador-pagador, ${ }^{39}$ ya que la permisibilidad de la actividad termina asintiendo emisiones de contaminación.

Cabe en este punto subrayar que el test de razonabilidad ${ }^{40}$ empleado para determinar las exenciones del IACV no ha denotado cuál es el objetivo perseguido a través

36. Entiéndase por aspecto espacial el que localiza el lugar de producción del hecho imponible; véase Geraldo Ataliba, Hipótesis de la incidencia tributaria (Lima: Instituto Peruano de Derecho Tributario, 1987). Disponible en 〈http://www.mpfn.gob.pe/escuela/contenido/actividades/docs/2201_2_hipotesis_de_incidencias_tributaria.pdf).

37. Ley No. 0, publicada en Registro Oficial Suplemento 744, de 29 de abril de $201 \overline{6}$.

38. Considérese que en la L.F.A.O.I.E., los autos con cilindraje 1.500 cc están considerados como supuestos de no sujeción ya que, sin importar su año de fabricación, no provocan el nacimiento del IACV; lo que denota el quiebre de la relación de la base imponible entre los parámetros considerados susceptibles de producir daño ambiental, sobre todo si se reflexiona que muchos de ellos quedan rezagados de la matriculación vehicular por no pasar la CORPAIRE.

39. European Comission, "Principles of EU Enviromental Law", 2012. Disponible en 〈http://ec.europa.eu/environ ment/legal/law/pdf/principles/2\%20Polluter\%20Pays\%20Principle_revised.pdf

40. Corte Constitucional del Ecuador, Test de Razonabilidad, Sentencia No. 019-16-SIN-CC, 22 de marzo de 2016. 
del establecimiento de trato desigual, ni ha sopesado si este ha sido propuesto a la luz de la Constitución; peor aún, no ha balanceado la proporcionalidad entre ese trato y el fin perseguido. Estas observaciones podrían apuntarse ad infinitum, sin embargo con lo indicado se demuestra la necesidad de reajuste de estas exenciones que rompen la igualdad formal, admitiendo a pocos el disfrute gratuito del ambiente sin importar los costes intra e intergeneracionales que la polución implica.

La Ley de Fomento Ambiental y Optimización de los Ingresos del Estado (LFAOIE), aunque constitucionalmente resulte cuestionable, también prevé para el IACV un supuesto de sujeción respecto de los automotores cuyo cilindraje es inferior a los $1500 \mathrm{cc}$. Vale resaltar que la atenuación a la regla impositiva es viable a la luz de márgenes de un mínimo exento ya que técnicamente viene a ser factible en virtud de relacionarse en forma directa con el criterio legal contaminante -objeto imponible-centímetros cúbicos de cilindraje, y a la par se evita el aniquilamiento de recursos a los propietarios de esa clase de vehículos.

Con lo referido, filtrando las enseñanzas del profesor Ramiro Ávila, se comprende que el derecho fundamental a un mínimo vital "constituye un límite al poder impositivo del Estado y un mandato que orienta la intervención del Estado en la economía [...] que coincide con las competencias, condiciones básicas y prestaciones sociales para que la persona humana pueda llevar una vida libre de las cargas de la miseria". ${ }^{41}$ Por tanto, ante el desatino de conceder a manifestaciones evidentes de capacidad económica, solamente tendría cabida ante la contaminación provocada por justa causa en garantía de otros derechos humanos de mayor peso, como por ejemplo el de la salud -mediante el uso de ambulancias-. Además, se plasma que el IACV refleja inconsistencias de la política de subsidios a combustibles que lleva el Ecuador, ya que mediante estos se incita al contribuyente a su consumo, mientras que el IACV no grava el factor recorrido-contaminación.

\section{MODULACIÓN DEL PRINCIPIO DE CAPACIDAD CONTRIBUTIVA EN SUS JUSTOS LÍMITES}

Según García Etchegoyen, en términos de justicia existen dos aspectos que convergen en una sola tesis respecto al principio de capacidad contributiva que en lo atinente a la imposición extrafiscal deben observarse.

41. Ramiro Ávila Santamaría, Justicia tributaria: pensamientos doctrinarios y jurisprudenciales sala especializada de lo contencioso tributario (Quito: Corte Nacional de Justicia, 2013), 61. 
El primero hace referencia a que la acción promocional del Estado no solo debe regir en materia de ingresos conforme lo hacen los impuestos ortodoxos, sino que se puede encumbrar otros objetivos; y el segundo aspecto lo vincula con la solidaridad, como criterio idóneo para la reasignación de recursos colectados, ayudando a la redistribución de los ingreso. ${ }^{42}$ Esta inflexión moderna al principio estudiado ha tenido cabida en Ecuador mediante la extrafiscalidad, pues remitiéndose al artículo 30 de la Constitución de la República del Ecuador, donde se consagra el derecho de las personas a un hábitat seguro y saludable, vinculando a los fines de la política tributaria constante en el artículo 300, de manera implícita en términos de justicia social se ha abordado a la capacidad contributiva. Así, a propósito de la ley tributaria, en el IACV se respeta y garantiza la capacidad contributiva dado que permite gravar indicios de capacidad económica para el pago del tributo en beneficio social.

De su parte, Miguel Martínez Lago ${ }^{43}$ propugna que aludir a la modulación de la capacidad contributiva implica pensar a través de la clave de solidaridad, por medio de la cual han de repartirse las cargas públicas inspiradas en las exigencias de intereses colectivos. De allí, se resalta, jamás la capacidad contributiva puede considerarse aislada a las exigencias sociales, dado que la carga tributaria no solo aumenta o disminuye subyaciendo a criterios de idoneidad de la contribución, sino que constitucionalmente lo hace también por razones de interés colectivo o social. ${ }^{44}$ Por ende, la modulación de la capacidad contributiva no implica vaciarla de contenido, sino que bajo el presupuesto de que no se establezcan diferenciaciones discriminatorias o arbitrarias que vulneren el principio de igualdad en la justa repartición de la carga impositiva, la imposición extrafiscal puede gravar hechos u objetos contaminantes -que por supuesto reportan beneficio para el agente contaminador- para conquistar fines extrarrecaudatorios. Por esta razón, se puede aseverar que los criterios de capacidad contributiva son equitativamente canjeables con la conveniencia de justicia social y bien común.

En consecuencia, se debe comprender que en materia impositiva el criterio de justicia no opera de la misma manera que en los tributos con estructura contributiva, de financiación o recaudatorios donde opera bajo el criterio de contribución o de pago,

42. Marcos F. García Etchegoyen, El principio de capacidad contributiva: evolución dogmática y proyección en el derecho argentino (Buenos Aires: Ábaco de Rodolfo Depalma, 2004), 143.

43. Miguel Ángel Martínez Lago, "Una interpretación constitucional de la funcionalidad de la capacidad económica como principio informador del ordenamiento financiero", Revista Española de Derecho Financiero, No. 55 (1987).

44. Gemma Paton García indicó que en Latinoamérica el desarrollo económico es directamente proporcional con el agravamiento de los problemas ambientales, y que se justifica la necesidad de contribuir para atenuarlos. Véase Gemma Patón García, Una apuesta por el establecimiento de impuestos verdes en países emergentes $y$ en desarrollo (Quito: Fundación Friedrich Ebert, 2012). Disponible en «http:/library.fes.de/pdf-files/bueros/ quito/09072.pdf〉. 
sino que en los tributos extrafiscales lo hace como fuente, substrato o exigencia lógica de la imposición como criterio social de retribución, corrección o prevención, quedando de esta manera válidos y legitimados los impuestos extrafiscales. Dino Jarach ${ }^{45}$ expone que la capacidad contributiva no es solamente un criterio de medición sino que debe interpretarse de acuerdo con los fines y propósitos que el legislador persigue con la tributación, añadiendo que no se puede desconocer más allá de lo razonable y tolerable, la susceptibilidad de imposición de los contribuyentes. ${ }^{46}$

\section{CONCLUSIONES}

1. La extrafiscalidad ambiental se fraguó a través de la tendencia moderna en la que las políticas públicas son el instrumento que efectivizan cometidos constitucionales, para garantizar derechos de los individuos, como es al ambiente sano.

2. El destino del ingreso que proviene de los recursos tributarios extrafiscales no se agota en su mismo fin, sino que coadyuva al sostenimiento del gasto público para cubrir las necesidades públicas erga omnes.

3. El principio el que contamina paga, robustece la firmeza de los impuestos ambientales a través de la determinación del sujeto pasivo y del hecho tipificado como presupuesto de hecho para soportar el gravamen; además permite que se concrete el fin de la extrafiscalidad ya que incide directamente en el agente contaminador moldeando su conducta en pro del ambiente.

4. El impuesto a la contaminación vehicular está desarticulado con el fin extrafiscal por la incoherente política de subsidios a los combustibles, y por tanto debe rediseñarse bajo criterios que graven en forma fidedigna picos de polución, y respetando los principios: el que contamina paga y equidad horizontal.

5. La capacidad contributiva en materia extrafiscal no desatiende manifestaciones de riqueza del contribuyente, sino que atiende intereses colectivos para gravar la polución, afanando el ejercicio y goce de derechos constitucionales.

45. Marcos Dino Jarach, Curso superior de Derecho tributario (Buenos Aires: Cima, 1969), 129.

46. García Etchegoyen, El principio de capacidad contributiva evolución dogmática y proyección en el derecho argentino (Buenos Aires: Ábaco, 2004), 149. 


\section{BIBLIOGRAFÍA}

Arnaldo, Antonio. Los impuestos ambientales. Buenos Aires: Osmar D. Buyatti Librería, 2007.

Asociación Argentina de Estudios Fiscales, Tratado de tributación. Buenos Aires: Astrea, 2003.

Ataliba, Geraldo. Hipótesis de la incidencia tributaria. Lima: Instituto Peruano de Derecho Tributario, 1987. Disponible en 〈http://www.mpfn.gob.pe/escuela/contenido/actividades/ docs/2201_2_hipotesis_de_incidencias_tributaria.pdf .

Ávila Santamaría, Ramiro. Justicia tributaria: pensamientos doctrinarios y jurisprudenciales sala especializada de lo contencioso tributario. Quito: Corte Nacional de Justicia, 2013.

Cruz de Quiñónez, Lucy. "Marco constitucional del derecho tributario". En La jurisprudencia tributaria del consejo de estado estudio. Bogotá: Instituto Colombiano de Derecho, 2004.

De Bujanda Sainz, Fernando. Hacienda y Derecho. Madrid: Instituto de Estudios Políticos, 2015.

De la Torre, Jefferson. “Gestión de Políticas Públicas”. Serie Académica Equinoccio, No. 2. Quito: Universidad Tecnológica Equinoccial, s. a.

Dino Jarach, Marcos. Curso Superior de Derecho Tributario. Buenos Aires: Cima, 1969.

European Comission, "Principles of EU Enviromental Law", 2012. Disponible en «http:// ec.europa.eu/environment/legal/law/pdf/principles/2\%20Polluter\%20Pays\%20Principle revised.pdf〉.

Fanelli, José María, Juan Pablo Jiménez e Isabel López Azcúnaga. La reforma fiscal ambiental en América Latina. Santiago de Chile: Naciones Unidas, 2015. Disponible en $/$ http://repositorio.cepal.org/bitstream/handle/11362/39782/S1501147_es.pdf;jsessionid=1C2F687E4 53F752541DC1085C43B3708? sequence $=1$ ).

Figueroa Neri, Aimée. Fiscalidad y medio ambiente en México. México: Porrúa, 2000.

García Alarcón, Gloria. "Son los tributos ambientales una opción para la financiación de las HHPP? Reflexiones sobre la fiscalidad ambiental autonómica”. Cuides, No. 9 (2012).

García Etchegoyen, Marcos F. El principio de capacidad contributiva: evolución dogmática y proyección en el derecho argentino. Buenos Aires: Ábaco de Rodolfo Depalma, 2004.

Leicester, Andrew. “Tributación medioambiental: Principios económicos y experiencia en el Reino Unido”. En Energía y tributación ambiental. Madrid: Marcial Pons, 2013.

Martínez Lago, Miguel Ángel. "Una interpretación constitucional de la funcionalidad de la capacidad económica como principio informador del ordenamiento financiero". Revista Española de Derecho Financiero, No. 55 (1987).

Organización para la Cooperación y el Desarrollo Económico/Agencia Internacional de la Energía. Environmentaltaxes- A statistical guide European Communities. Una apuesta por el establecimiento de impuestos verdes en países emergentes y en desarrollo. Quito: Fundación Friedrich Ebert Stiftung, 2012. Disponible en «http://library.fes.de/pdf-files/bueros/ quito/09072.pdf>. 
Ortega Perfecto Yebra, Martul. "Los fines extrafiscales del impuesto". En Andrea Amatucci, Tratado de derecho tributario: el derecho tributario y sus fuentes. Bogotá: Temis, 2001.

Páez Medina, María Elena. "La capacidad contributiva en los tributos medioambientales". Tesis doctoral, Universidad de Salamanca, 2012. Disponible en «http://gredos.usal.es/jspui/ bitstream/10366/115606/1/DDAFP_Paez_Medina_M_Elena_LaCapacidadContributiva TributosMedioambientales.pdf〉.

Patón García, Gemma. Una apuesta por el establecimiento de impuestos verdes en países emergentes y en desarrollo. Quito: Fundación Friedrich Ebert, 2012. Disponible en 〈http:// library.fes.de/pdf-files/bueros/quito/09072.pdf).

Pigou, Arthur. A study in public finance. Londres: Macmillan and Co., 1928.

---. The Economics of Welfare. Londres: Macmillan and Co., 1920.

Pistone, Pasquale. Estudios de Derecho tributario constitucional e internacional: homenaje latinoamericano a Victor Uckmar. Buenos Aires: 2005.

Plan Nacional del Buen Vivir 2009-2013, 2009. Disponible en «ttp://www.planificacion.gob. ec/wpontent/uploads/downloads/2012/07/Plan_Nacional_para_el_Buen_Vivir (version_re sumida_en_espanol).pdf〉.

Queralt, Juan Martín, y otros. Curso de Derecho financiero y tributario. Madrid: Tecnos, 2015.

Rozo Gutiérrez, Carolina. "Las funciones extrafiscales del tributo a propósito de la tributación medioambiental en el ordenamiento jurídico colombiano". Foro: Revista de Derecho, No. 1 (2003).

Sánchez Galiana, José Antonio. “Configuración y régimen jurídico de las tasas en el ordenamiento tributario español. Fiscalidad, parafiscalidad y extrafiscalidad". En Andrea Amatucci, Dal diritto finanziario al diritto tributario: studi in onore di Andrea Amatucci. Bogotá: Temis/Jovene, 2012.

Villegas, Héctor B. Ciencia de las finanzas y activ idad financiera, 3a. ed. Buenos Aires, 1984.

Vogel, Klaus. "Von einer Emeuerung des Allgemeinen Abgabenrechts in Deutschland". En Perfecto Yebra Martul Ortega, Los fines extrafiscales del impuesto. Bogotá: Temis, 2002.

\section{OTROS}

Asamblea Nacional de la República del Ecuador.

Código Orgánico de la Producción, Comercio e Inversiones. R. O. 351, 29 de diciembre de 2010. Disponible en 〈http://www.wipo.int/edocs/lexdocs/laws/es/ec/ec050es.pdf〉.

Constitución de la República del Ecuador. Montecristi, 2008. Disponible en 〈http://www. asambleanacional.gov.ec/documentos/constitucion_de_bolsillo.pdf).

Corte Constitucional de Colombia.

Corte Constitucional del Ecuador. 